Severe emotional deprivation with reversible failure of growth hormone release has been recognized as an important cause of growth failure. ${ }^{4}$ This work in Newcastle has documented the association of adverse family circumstances with growth retardation in children in whom growth hormone levels are normal. Factors such as long periods of paternal unemployment, imprisonment, parental separation, and the state of the home assessed by a health visitor were used to give an objective social score, from which it was concluded that in at least one third of these small, normal children impaired physical development was due to the poor home environment. In addition, children from emotionally deprived homes also had significantly lower intellectual attainment than children from appropriate control families without such adverse home backgrounds.

The relative role of genetic and environmental factors cannot yet be fully unravelled, but an association has been established between growth retardation and impaired intelligence on the one hand and particularly bad family circumstances on the other. Short stature should thus alert the physician, the family doctor, community physician, or paediatrician to the possibility of severe social deprivation. The remedy may well be out with his power, lying rather with society's attitude to the less-favoured than in the efficiency of such social agencies he may call upon. But for future generations a feeling of obligation to the underprivileged must be backed with improved educational services in general and instruction into the responsibilities of parenthood, in particular, especially in the most socially deprived areas.

1 Harris, F., Medicine, 1974, 27, 1600.

2 Lacey, K. A., and Parkin, J. M., Lancet, 1974, 1, 42.

3 Lacey, K. A., and Parkin, J. M., Archives of Diseases in Childhood, 1974, 49, 417 .

${ }^{4}$ Powell, G. F., Brasel, J. A., and Blizzard, R. M., New England Fournal of Medicine, 1967, 276, 1271 .

\section{Review of Meniscectomies}

Meniscectomy is one of the most popular orthopaedic operations, but as Fairbank ${ }^{1}$ pointed out in 1948 it is not a wholly innocuous procedure. He found radiographic changes in $37 \%$ of 107 patients examined from three months to four years after operation. These included ridging and flattening of the appropriate femoral condyle and narrowing of the joint space, either singly or in combination. He concluded that meniscectomy interferes at least temporarily with the mechanics of the joint and suggested that the changes seen might be the precursors of osteoarthritis.

More recently Jackson ${ }^{2}$ compared the radiographs of both knees in 577 patients five or more years after operation on one knee only. He found that degenerative change occurred in $21 \%$ of post-meniscectomy knees and in only $5 \%$ of the controls. Though degeneration increased in both knees with the length of follow-up meniscectomy precipitated a much greater change. He also found that the length of time that the patient had had his symptoms before surgery had no effect on the severity of the degeneration found later. Jackson stressed that radiographic changes in the knee did not necessarily mean that the patient had symptoms in the joint, but he thought that a more conservative attitude to meniscectomy should be adopted. Even at arthrotomy he advised that all other structures should be examined carefully before a normal-looking meniscus was excised. He suggested that a long period of preoperative observation be undertaken if there was any doubt that the meniscus was torn-and added that there might be medicolegal implications, since a man whose meniscus was removed in his 20 s would risk osteoarthrosis in the joint by his 50 s, and a manual worker might need to change his job.

A more detailed report of the long-term results of meniscectomy has now been published by Johnson et al..$^{3}$ from Iowa. They examined 99 patients 5-37 years after surgery. All these patients had had the operation performed on one knee only, the other knee being used as a control and they found that $42.5 \%$ had satisfactory results and $57.5 \%$ unsatisfactory. Men were found to have recovered better from surgery than women, especially if the medial meniscus alone had been excised; if the posterior horn was not excised the results were unsatisfactory; while the status of the surgeon performing the operation did not affect the prognosis. In contrast with Jackson's experience, Johnson and his colleagues found there was a connexion between the result and the length of time between onset of symptoms and surgery. They acknowledged that they differed from other authors on this point, and suggested that it might not be the length of time the patients had had his symptoms but the trauma of repeated locking and collapsing that led to the poor prognosis. More patients had ligamentous laxity postoperatively than preoperatively, and these patients had unsatisfactory results. Rotational instability was increased and passive motion reduced in some patients. These were also associated with poor results, as was quadriceps atrophy, which occurred in 30 of the 99 patients. At least one of Fairbank's changes on radiography was found in $74 \%$ of the knees, and the frequency of unsatisfactory results increased with the number of changes found.

So from both sides of the Atlantic there is evidence of the many problems that may follow excision of a structure whose function is not fully understood. The message from these studies, however, is easy to understand: a torn meniscus giving symptoms must be excised, but if the meniscus can be left in the joint it should be.

1 Fairbank, T. J., Fournal of Bone and Foint Surgery, 1948, 30, 664.

2 Jackson, J. P., British Medical fournal, 1968, 2, 525.

3 Johnson, R. J., et al., fournal of Bone and foint Surgery, 1974, 56, 719.

\section{Biochemical Basis of Migraine}

The idea that a unifying biochemical cause underlies both the migrainous diathesis and the precipitation of attacks of migraine has always been seductive-and receives some support from the observed effect of diet. A proportion of migraine sufferers claim that their attacks are triggered by certain foods, notably cheese, chocolate, and citrus fruits, and, even more frequently, by alcohol, particularly red wine. Unfortunately, avoidance of these substances seldom leads to cure, and the relationship appears to be complex. Even though in patients who had observed an adverse effect of chocolate the consumption of disguised chocolate under controlled conditions did not induce migraine, ${ }^{1}$ the dietary clue is promising. Tyramine, already incriminated in the headache and hypertension induced by eating cheese in patients taking monoamine oxidase inhibitors, ${ }^{2}$ was at first suspected, though hypertension is not a feature of the migraine attack. A failure to metabolize tyramine has been reported in some migrainous subjects, ${ }^{3}$ but under laboratory conditions tyramine does not induce migraine, ${ }^{4}$ and the E.E.G. changes reported to follow its ingestion are difficult to equate with the underlying mechanisms of headache. ${ }^{5}$ 